\title{
The effect of maternal hypercholesterolemia on the placenta and fetal arteries in rabbits ${ }^{1}$
}

\author{
Efeito da hipercolesterolemia maternal sobre a placenta e as artérias fetais em coelhos
}

\begin{abstract}
Elemara Frantz', Honório Sampaio Menezes ${ }^{\mathrm{II}}$, Kellyn Cristine Lange ${ }^{\mathrm{III}}$, Milena Pacheco Abegg ${ }^{\mathrm{IV}}$, Cora Albrecht Correa ${ }^{\mathrm{IV}}$, Leoni Zangalli $^{\mathrm{V}}$, Jefferson Luís Vieira ${ }^{\mathrm{IV}}$, Cláudio Galeano Zettler ${ }^{\mathrm{VI}}$

IFellow Master degree, IC/FUC, Porto Alegre-RS, Brazil. Acquisition and interpretation of data, statistical analyses and scientific content of the study. IIPhD, Assistant Professor, IC/FUC, Porto Alegre-RS, Brazil. Main author, conception, design, critical review of the study.

IIIFellow Master degree, IC/FUC, Porto Alegre-RS, Brazil. Acquisition and interpretation of data, statistical analyses and scientific content of the study. ${ }^{\text {IV }}$ Graduate student, Experimental Medicine Group, Lutheran University of Brazil (ULBRA), Canoas-RS, Brazil. Animal care and acquisition of data. vAssistant Professor, ULBRA, Canoas-RS, Brazil. Nutrition and special diet care of laboratory animal.

${ }^{\mathrm{V}} \mathrm{PhD}$, Assistant Professor, ULBRA, Canoas-RS, Brazil. Analysis and pathology data interpretation.
\end{abstract}

\begin{abstract}
PURPOSE: To investigate the degree of placental permeability in dyslipidemic rabbits and the consequent vascular dysfunction in fetuses of female rabbits with high lipoprotein levels.

METHODS: Fifteen adult females New Zealand White rabbits were divided into two groups. Group 1(n=5) - hypercholesterolemic diet with $0.5 \%$ cholesterol, and Group $2(\mathrm{n}=10)$ - control. On day 30, the levels of plasma lipoproteins and triglycerides were analyzed in the mothers, and the presence of collagen was analyzed in the placenta as well as in fetal coronary and aorta. Statistical analyses used the Student's $t$ and the Mann-Whitney tests.

RESULTS: Lipoprotein levels were significantly different $(\mathrm{p}=0.02$ to $\mathrm{p}<0.001)$ in experimental and control groups. In the hypercholesterolemic group, total cholesterol levels were in average 793mg/dl; triglycerides were in average 257mg/dl; HDL-C was 48mg/ $\mathrm{dl}$, and LDL-C was in average $692 \mathrm{mg} / \mathrm{dl}$. The amount of collagen per micrometers square $\left(\mathrm{m} \mu^{2}\right)$ in samples from hypercholesterolemic animals was significantly higher than in the control group.

CONCLUSIONS: The study confirmed placental permeability to lipoproteins, shown by increased amounts of collagen in fetal tissues. This alteration results in increased susceptibility to atherosclerosis in adult life, representing a risk factor for the early development of disease, which may appear even in the prenatal period.
\end{abstract}

Key words: Dyslipidemias. Cholesterol. Collagen. Rabbits.

\section{RESUMO}

OBJETIVO: Investigar a permeabilidade placentária em coelhos adultos fêmeas dislipidêmicas e a consequente disfunção vascular em seus fetos.

MÉTODOS: Quinze coelhos adultos fêmeas Nova Zelândia Brancas foram distribuídas em grupo dislipidêmico e grupo controle. No trigésimo dia de gestação foram medidos os triglicerídeos e as lipoproteínas nas coelhas e verificada a presença de colágeno na placenta e coronárias fetais. Análise estatística foi feita com teste t de Student's e Mann-Whitney.

RESULTADOS: Os níveis de lipoproteínas foram diferentes estatisticamente entre os grupos ( $p=0,02$ a $p<0,001)$. A quantidade de colágeno por micrômetro quadrado foi significantemente maior no grupo hipercolesterolêmico em comparação ao grupo controle.

CONCLUSÕES: O estudo confirmou a permeabilidade placentária para lipoproteínas demonstrando aumento de colágeno nos tecidos fetais. Esta alteração induz ao aumento da suscetibilidade para aterosclerose na vida adulta, representando um fator de risco para desenvolvimento precoce da doença aterosclerótica a qual pode estar presente mesmo no período pré-natal.

Descritores: Dislipidemias. Colesterol. Colágeno. Coelhos. 


\section{Introduction}

Coronary artery disease (CAD) most often results from an increase in the plasma levels of low-density lipoprotein cholesterol (LDL-C) and modifications in the metabolism of this lipoprotein, associated to other risk factors ${ }^{1}$. To decrease the high morbidity and mortality rates associated to CAD, other approaches such as lifestyle changes should be instituted in parallel with drug therapy ${ }^{2}$.

The placenta transfers up to $50 \%$ of the fatty acids needed by the fetus during the third trimester pregnancy. The presence of lipoprotein lipase in other placental membranes results in the degradation of triglycerides and lipoproteins, particularly verylow density lipoprotein (VLDL) ${ }^{3}$. Increased levels of high-density lipoprotein cholesterol (HDL-C) and low-density lipoprotein cholesterol (LDL-C) in the umbilical venous plasma may be due to increased placental permeability, resulting in the transfer of cholesterol to the fetal circulation ${ }^{4}$.

The structure of the extracellular matrix (ECM) is related to its role in regeneration, scarring and fibrosis. The synthesis and degradation of ECM components depend on processes of morphogenesis, scarring and chronic fibrosis. The ECM is composed of fibrous proteins, such as collagen and elastin, adherent glycoproteins, proteoglycans and hyaluronic acid, grouped in the interstitial matrix and basal membrane. The interstitial matrix is distributed among epithelial and endothelial cells and smooth muscle fibers, and includes components such as fibrillar and nonfibrillar collagen and elastin ${ }^{5,6}$. Collagen type VIII, one of the ECM components, is responsible for the reorganization observed during experimental atherosclerosis. Collagen deposition, associated to cholesterol levels, probably has a role in the structural and functional remodelling of the intima ${ }^{7}$.

Collagen and elastin are the main components of the extracellular matrix and arterial walls, ensuring the elasticity and maintenance of vessels walls. They are less flexible in the walls of damaged blood vessels, which are harder and have reduced vascular compliance in hypertension ${ }^{8}$.

Elasticity is important for the adequate function of blood vessels, skin, uterus and lungs. The tensile strength is provided by proteins of the collagen family, and elastic fibers give to the tissue the ability to recoil and extend to the original length many times after tension. Elastin exists in abundance in the walls of large blood vessels such as the aorta, as well as in the uterus, skin and ligaments ${ }^{5,6}$.

The present study aimed to compare the vascular and cellular morphology of the placenta in hypercholesterolemic or normal female rabbits, and to analyze placental permeability to lipoproteins as well as its effect on the metabolism of collagen in fetal vessels (coronary and abdominal aorta).

\section{Methods}

Fifteen adult New Zealand White rabbits were used in this experimental study. During the initial period, the animals were maintained in individual cages, at $18^{\circ} \mathrm{C}$ to $24^{\circ} \mathrm{C}$, and were fed on a standard rabbit's diet (Nuvilab rabbit chow) and water ad libitum.

After breeding, the females were divided into two groups. Five rabbits (group 1) received a hypercholesterolemic diet, and 10 rabbits (group 2) were fed with a normal diet. The hypercholesterolemic diet was prepared with $0.5 \%(\mathrm{w} / \mathrm{w})$ cholesterol $/ \mathrm{kg}$ diet ( $5 \mathrm{~g}$ cholesterol and $150 \mathrm{~g}$ coconut fat $/ \mathrm{kg}$ rabbit chow).

On day 30, the female rabbits were anesthetized with ketamine and xylazine and sacrificed in $\mathrm{CO}_{2}$ chambers for performance of caesarian sections. Peripheral blood and placenta were collected from the female rabbits, and coronary and abdominal aorta samples were collected from the fetuses, for analysis of plasma cholesterol, lipoproteins, collagen and changes in the fetal vasculature. The organs were fixed in 10\% formalin solution, in closed vials, and included in paraffin. Sections were stained with Masson's trichrome and analyzed with a Motic DMB1-223, B-1 series microscope. Images were obtained with 10 and 40x magnification. The presence of collagen was determined with the Image - Pro Plus 6.0 system.

Plasma cholesterol (CT) levels were analyzed in duplicate samples from group 1 rabbits, to validate the method and to identify hypercholesterolemia, and in one sample from group 2 normal animals. Hypercholesterolemia was defined as plasma cholesterol levels above $5.18 \mathrm{mmol} / \mathrm{L}$ (200 mg/dl). Other laboratory analyses, including triclycerides (T), HDL-C and LDL-C, were conducted by the Cediclin Laboratory, in Canoas/RS.

Results were recorded with the Microsoft Excel software. Statistical analyses were performed with the non-parametric Mann-Whitney and Student's t test, using the SPSS 14 software. The significance level was established at $5 \%(p<0.05)$. The experimental protocol was approved by the institutional Research Ethics Committee.

\section{Results}

As presented in Table 1, samples from group 1 (hypercholesterolemic) rabbits presented significantly higher 
levels of CT, HDL-C, TG and LDL-C than samples from group 2 (normocholesterolemic) animals $(\mathrm{p} \leq 0.001)$ (Table 1 and Figure 1).

TABLE 1 - Blood levels of lipoproteins in rabbits from groups 1 and 2 on the $30^{\text {th }}$ day of pregnancy, when caesarian sections were performed. Results (mg/dl blood) are presented as mean \pm standard deviation.

\begin{tabular}{cccc}
\hline & $\begin{array}{c}\text { Hypercholesterolemic } \\
\text { Group=1 } \\
\mathbf{n}=\mathbf{5}\end{array}$ & $\begin{array}{c}\text { Normocholesterolemic } \\
\text { Group=2 } \\
\mathbf{n}=\mathbf{1 0}\end{array}$ & p* \\
\hline CT & $793.00 \pm 67.45$ & $66.45 \pm 4.05$ & $<0.001$ \\
HDL-C & $48.80 \pm 6.83$ & $18.40 \pm 0.97$ & 0.001 \\
TG & $257.80 \pm 19.36$ & $44.70 \pm 4.32$ & $<0.001$ \\
& & & \\
LDL-C & $692.64 \pm 61.76$ & $39.46 \pm 3.54$ & $<0.001$ \\
\hline
\end{tabular}

*Student's t test
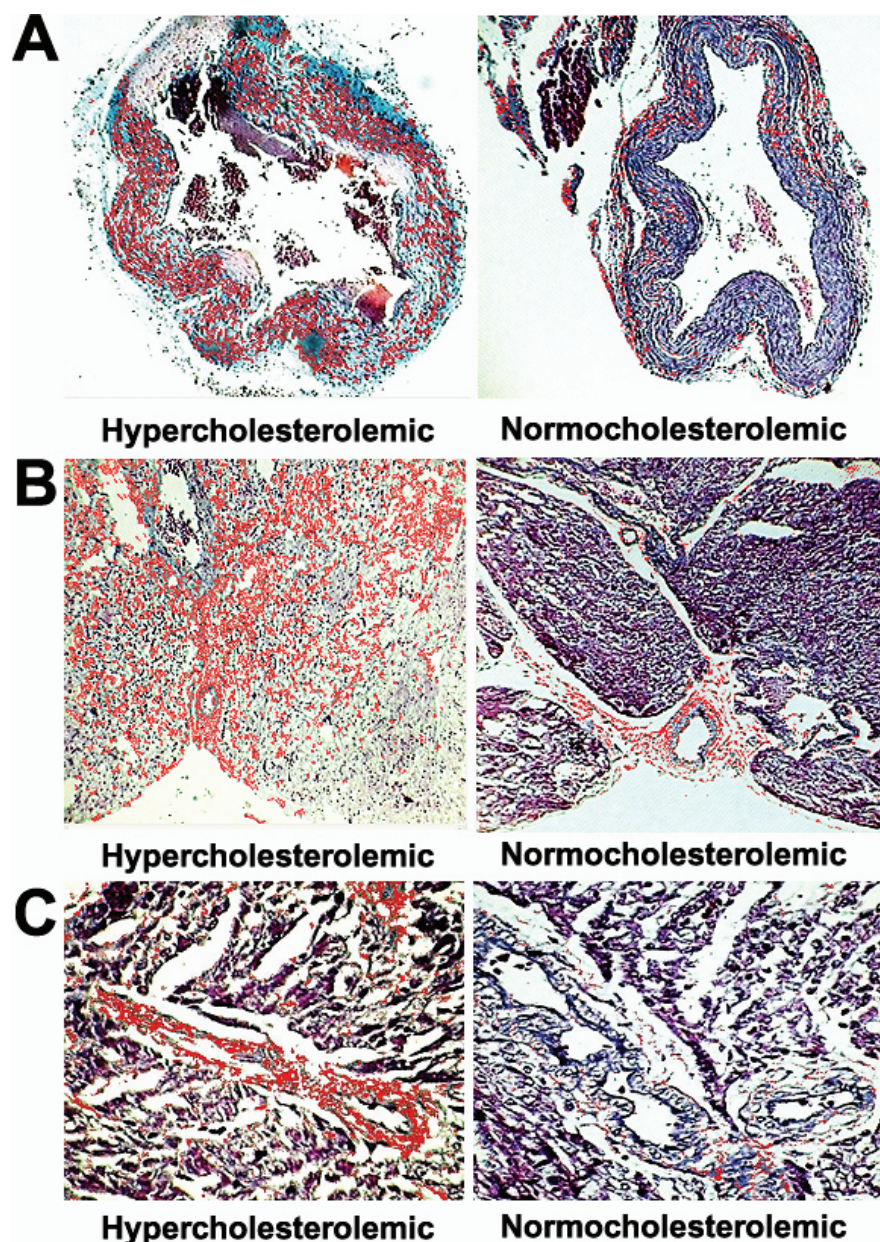

Normocholesterolemic

FIGURE 1 - Comparative collagen (red): (a) aorta, (b) placenta, (c) coronary.
Collagen levels were higher in fetuses of the hypercholesterolemic group, in samples collected from the three tissues: aorta $(\mathrm{p} \leq 0.026)$, placenta $(\mathrm{p}<0.002)$ and coronary $(\mathrm{p}<0.001)$ (Table 2).

TABLE 2 - Collagen levels (in micrometers) determined by image analysis of samples from groups 1 and 2 . Results are presented as median (25-75 percentile).

\begin{tabular}{lccccccc}
\hline & \multicolumn{3}{c}{ Hypercholesterolemic Group=1 } & \multicolumn{3}{c}{ Normocholesterolemic Group=2 } \\
\cline { 2 - 8 } Collagen & $\mathrm{n}$ & median & $\left(\mathrm{P}_{25}-\mathrm{P}_{75}\right)$ & $\mathrm{n}$ & median & $\left(\mathrm{P}_{25}-\mathrm{P}_{75}\right)$ & $\mathrm{p}^{*}$ \\
\hline Aorta & 7 & 418,336 & $(269,400 ; 648,710)$ & 7 & 28,894 & $(14,391 ; 65,882)$ & 0.026 \\
Placenta & 15 & 383,949 & $(110,737 ; 794,573)$ & 8 & 40,562 & $(20,354 ; 74,159)$ & 0.002 \\
Coronary & 17 & 1,910 & $(1,618 ; 2,330)$ & 8 & 201 & $(136 ; 242)$ & $<0.001$ \\
\hline
\end{tabular}

*Mann-Whitney test

\section{Discussion}

As presented in Table 1, higher levels of the lipoproteins CT, TG and LDL-C were observed in animals from group 1 as compared to group $2(\mathrm{p} \leq 0.001)$. HDL-C levels were also higher in group $1(p=0.001)$. These results confirm that rabbits from group 1 became hypercholesterolemic after receiving the hypercholesterolemic diet and validate the experimental model used in this study ${ }^{4,9}$.

The increase in HDL-C levels observed in rabbits from group 1 represents a protective factor ${ }^{1}$. Previous studies have shown that, in CAD, levels of HDL-C above $40 \mathrm{mg} / \mathrm{dl}$ are protective and are associated to decreased risk for atherosclerosis ${ }^{1,10}$. As shown in Table 1, however, the levels of the other lipoproteins investigated (CT, TG and LDL-C) were also high, representing a risk factor for CAD even with normal levels of HDL-C. Opposite results were observed for animals in group 2, where low HDL-C levels do not protect against $\mathrm{CAD}$, even with normal levels for the other lipoproteins investigated.

The high LDL-C levels observed in group 1 show that the special diet induced hypercholesterolemia in the rabbits, with a consequent susceptibility to the atherogenic process in artery walls. High levels of LDL-C have been previously reported in similar studies ${ }^{4,11}$.

Increased TG levels in group 1 indicate mixed hyperlipidemia, a condition characterized by high levels of LDL-C $(\geq 160 \mathrm{mg} / \mathrm{dl})$ and $\mathrm{TG}(\geq 150 \mathrm{mg} / \mathrm{dl})^{1}$. The existence of mixed hyperlipidemia and the significant differences observed between the experimental groups suggest the development of atherosclerotic processes in animals fed with the hypercholesterolemic diet. 
Analyses of coronary and abdominal aorta samples from fetuses of hypercholesterolemic rabbits, presented in Table 2, show the effect of cholesterol, transferred from the mothers to the fetuses, on collagen synthesis. Similar results were observed for the placentas analyzed.

The present study showed abundant presence of collagen in arteries, in higher amounts in samples from group 1 than in group 2 , supporting the fact that collagen at physiological concentrations provides tensile strength in blood vessels. In elastic arteries, the media layer is rich in elastic fibers ${ }^{5}$. Our results also confirmed the existence of large amounts of collagen in arteries, with considerable relevance for the development of atherosclerosis, suggesting a process of rupture of the atherosclerotic plaque and release of collagen. The accumulation of lipids in the plaque is associated to loss of smooth muscle cells, showing increased synthesis of collagen, degradation and cell loss ${ }^{12}$. According to Stanley et al. ${ }^{5-}$ ${ }^{6}$, in type $\mathrm{V}$ lesions there is accelerated collagen deposition, and the atherosclerotic plaques have macrophages, ECM including collagen, elastic fibers and proteoglycans, as well as intracellular and extracellular lipids. Advanced type VI lesions present surface anomalies, hematoma and hemorrhage, and thrombus ${ }^{5}$.

Hyperlipidemia is associated to increased expression of the tropoelastin gene in the intima layer and lesions of foam cells. Collagen I is responsible for an increase in the resistance of arterial walls during hypertension, and collagen III has a role in cell-cell and cell-ECM interactions preserving the integrity of arterial walls, so that the structural and functional efficiency of the walls is preserved. Kawano et al..$^{14}$ analyzed rabbits in which hypercholesterolemia had been induced with a hypercholesterolemic diet. Atherosclerotic plaques in animals subsequently treated with eicosapentaenoic acid presented less foam cells and more collagen than in control rabbits. Despite a decrease in the number of foam cells and increased production of collagen in the treated group, the study showed that even in hypercholesterolemic untreated individuals there is collagen production in arteries. These results evidence low levels of production and release of collagen in hypercholesterolemia. The present study also showed the presence of collagen with formation of atherosclerotic plaques in the hypercholesterolemic group. Hypercholesterolemia resulted in loss of local collagen and loss of stability of the plaque ${ }^{14}$.

Our results showed that a diet enriched in $0.5 \%$ cholesterol is sufficient to raise the level of plasma cholesterol resulting in increased amounts of collagen in arterial walls, a basic component of atherosclerosis with formation of atherosclerotic plaques. The process is also seen in blood vessels in cases of high blood pressure, with a role in remodelling and recovery of the vessel after atherosclerosis develops ${ }^{12-14}$.

In this study, we observed a concentration of collagen in the placenta of hypercholesterolemic animals (Table 2). This result suggests that the $0.5 \%$ cholesterol diet resulted in atherosclerotic lesion in the placenta, due to the excess of collagen. Maternal hypercholesterolemia leads to increased susceptibility of the offspring to atherosclerotic processes, in adult life ${ }^{15}$. Our results also showed placental transfer of cholesterol, since the abdominal aorta and coronary of fetuses of hypercholesterolemic rabbits presented increased amounts of collagen, directly related to increased plasma levels of lipoproteins. It is known that the placenta transfers $50 \%$ of the fatty acids needed by the fetus during last trimester pregnancy, and that the placental membranes degrade fatty acids and lipoproteins ${ }^{3}$. Placental transfer, with increased levels of HDL-C and LDL-C observed in the umbilical venous plasma, results in significant amounts of lipoproteins in fetuses of hypercholesterolemic mothers with consequent induction of the atherosclerotic process. Our results also showed a direct relationship between increased levels of lipoproteins and the presence of collagen, evidencing the atherosclerotic process.

Heart samples from group 1 presented higher amounts of collagen than samples from group 2 (normal diet), showing the establishment of the atherosclerotic process in coronary arteries of fetuses of rabbits fed with the hypercholesterolemic diet during pregnancy. The myocardium has a highly organized network of extracellular matrix proteins that provide strength, flexibility and structural definition to the tissue. The matrix has large amounts of collagen type I, III and V, as well as a basis of collagen type $\mathrm{IV}^{16}$. This is the first study showing excess of collagen in this situation. The increased levels of lipoproteins also indicate the development of the atherosclerotic process, with abundant formation of collagen, in the cardiovascular tissue. This situation has also been investigated in cases of rupture of atherosclerotic plaques and loss of elastic tissue, probably in consequence of an attempt to remodel the heart and provide tensile strength to the tissues ${ }^{16}$. The relative concentration and organization of collagen fibers influence the physical characteristics of the cardiovascular tissue, particularly its distensibility (elasticity). The cardiovascular tissue and the vessels have a natural tensile strength, which is lost in the presence of atherosclerotic plaques, when rupture of the tissues result in release of collagen. It is possible that, in this event, the extracellular matrix is involved with the repair of injured tissues and return of the natural strength and elasticity to the tissue.

Hypercholesterolemic rabbits presented significantly higher levels of lipoproteins, showing that a $0.5 \%$ cholesterol- 
enriched diet results in significantly increased levels of plasma cholesterol. It has been postulated that maternal hypercholesterolemia during pregnancy is responsible for one cascade of pathogenic events, and is associated with greatly increased fatty streak formation in human fetal arteries and accelerated progression of atherosclerosis during childhood. Experiments in genetically more homogeneous rabbits established that temporary diet-induced maternal hypercholesterolemia is sufficient to enhance fetal lesion formation as we demonstrated in the present work ${ }^{17}$. A maternal high-fat diet, rich in saturated fatty acids (SFA), alters the lipid metabolism of their adult offspring, as demonstrated by Clechi, revealing the importance of diet control during pregnancy and childhood ${ }^{18}$. More important, maternal hypercholesterolemia appears to cause pathogenic events in the fetus increasing postnatal atherogenesis in response to hypercholesterolemia. Experiments in a murine model showed that differences in arterial gene expression between offspring of normo- and hypercholesterolemic mothers persist long after birth, supporting the assumption that fetal lesion formation, as ours work suggest, is associated with genetic programming, which may in turn affect postnatal atherogenesis. Comparative immunostaining for several genes also indicated increased protein content in offspring of hypercholesterolemic mothers indicating that atherogenic effect of maternal hypercholesterolemia in genetically uniform mice and also indicate that changes in aortic gene expression persist long after fetal exposure to hypercholesterolemia ${ }^{19}$.

Protein metabolism appears do not influence cholesterol as demonstrated by low protein diet (resulting in growth-restricted infants) throughout gestation in mice does not affect maternalfetal cholesterol transport, fetal cholesterol or fatty acid synthesis, indicating that programming effects of low protein diet are not mediated by short-term changes in maternal-fetal lipid metabolism, ours experimental groups were not submitted to diet restriction ${ }^{20}$.

The significantly higher amount of collagen in the abdominal aorta, heart and placenta of fetuses of hypercholesterolemic mothers as compared to fetuses of normal rabbits confirms the establishment of atherosclerosis.

Placental permeability to lipoproteins was shown by the relationship between increased levels of lipoproteins in the plasma of female rabbits and increased amounts of collagen in fetal tissues. High concentrations of lipoproteins in the fetuses result in increased susceptibility to coronary artery disease in adult life, representing a risk factor for the disease. The high amount of collagen in the fetal tissues analyzed confirms the existence of early alterations induced by maternal hypercholesterolemia.

\section{Conclusion}

Vascular dysfunction in coronary artery and abdominal aorta in fetuses of female rabbits feeded with cholesterol-enriched diet stresses the importance of prenatal control of lipoprotein levels, as a preventive factor against the early development of atherosclerosis.

\section{References}

1. Departamento de Aterosclerose da Sociedade Brasileira de Cardiologia: IV Diretrizes Brasileiras sobre Dislipidemias e Prevenção da Aterosclerose. Arq Bras Cardiol. 2007;88(Supl I):118.

2. Neves MQT, Bernik MMS, Nakandakare ER. Como diagnosticar e tratar dislipidemias. Rev Bras Med. 2005;62(12):6-15.

3. Martínez F, Espinosa-García MT, García C, Maldonado G, Milán R, Uribe A, Flores-Herrera O. Metabolismo energético y esteroidogénico de la placenta humana. Rev Fac Med UNAM. 2001;(44)5:201-5.

4. Parker CR Jr, Deahl T, Drewry P, Hankins G. Analysis of the potential for transfer of lipoprotein-cholesterol across the human placenta. Early Hum Dev. 1983;8(3-4):289-95.

5. Smith LT, Holbrook KA, Byers PH. Structure of the dermal matrix during development and in the adult. J Envest Dermatol. 1982;79:935-1045.

6. Lorenz HP, Adzik NS. Scarless skin wound repair in the fetus. J West J Med. 1993;159:350-5.

7. Shindo J, Ishibashi T, Yokoyama K, Nakazato K, Ohwada T, Shiomi M, Maruyama Y. Granulocyte-macrophage colony-stimulating factor prevents the progression of atherosclerosis via changes in the cellular and extracellular composition of atherosclerotic lesions in watanabe heritable hyperlipidemic rabbits. Circulation. 1999;99(16):2150-6.

8. Safar ME, Simon AC, Levenson JA. Structural changes of large arteries in sustained essential hypertension. Hypertension 1984;6(6 Pt 2):III117-21.

9. Brizzi P, Tonolo G, Esposito F, Puddu L, Dessole S, Maioli M, Milia S. Lipoprotein metabolism during normal pregnancy. Am J Obstet Gynecol. 1999;181(2):430-4.

10. Faludi AA, Bertolami MC, Aldrighi JM. Tratamento das dislipidemias nas mulheres. Rev Bras Cardiol. 2000;2(5):185-8.

11. Jaldin RG, Filho HAF, Sequeira JL, Yoshida WB. O processo aterosclerótico em artérias de coelhos submetidos à dieta suplementada com gema de ovo: modelo experimental de baixo custo. J Vasc Bras. 2006;5(4):247-56.

12. Brasselet C, Durand E, Addad F, Al Haj Zen A, Smeets MB, Laurent-Maquin D, Bouthors S, Bellon G, de Kleijn D, Godeau G, Garnotel R, Gogly B, Lafont A. Collagen and elastin cross-linking: a mechanism of constrictive remodeling after arterial injury. Am J Physiol Heart Circ Physiol. 2005;289(5):H2228-33.

13. Xu C, Zarins CK, Pannaraj PS, Bassiouny HS, Glagov S. Hypercholesterolemia superimposed by experimental hypertension induces differential distribution of collagen and elastin. Arterioscler Thromb Vasc Biol. 2000;20(12):2566-72.

14. Kawano H, Yano T, Mizuguchi K, Mochizuki H, Saito Y. Changes in aspects such as the collagenous fiber density and foam cell size of atherosclerotic lesions composed of foam cells, smooth muscle cells and fibrous components in rabbits caused by all-cis-5, $8,11,14$, 17-icosapentaenoic acid. J Atheroscler Thromb. 2002;9(4):170-7. 
15. Napoli C, Glass CK, Witztum JL, Deutsch R, Armiento FDP, Palinski. Influence of maternal hypercholesterolemia during pregnancy on progression of early atherosclerotic lesions in childhood: Fate of Early Lesions in Children (FELIC) study. Lancet. 1999;354(9186):1234-41.

16. Nakagawa S, Pawelek P, Grinnell F. Extracellular matrix organization modulates fibroblast growth and growth factor responsiveness. Exp Cell Res. 1989;182:572-82.

17. Palinski W, Napoli C. The fetal origins of atherosclerosis: maternal hypercholesterolemia, and cholesterol-lowering or antioxidant treatment during pregnancy influence in utero programming and postnatal susceptibility to atherogenesis. FASEB J. 2002;16(11):1348-60.

18. Chechi K, McGuire JJ, Cheema SK.Developmental programming of lipid metabolism and aortic vascular function in C57BL/6 mice: a novel study suggesting an involvement of LDL-receptor. Am J Physiol Regul Integr Comp Physiol. 2009;296(4):R1029-40.

19. Napoli C, de Nigris F, Welch JS, Calara FB, Stuart RO, Glass CK, Palinski W. Maternal hypercholesterolemia during pregnancy promotes early atherogenesis in LDL receptor-deficient mice and alters aortic gene expression determined by microarray. Circulation. 2002;105(11):1360-7.

20. van Meer H, van Straten EM, Baller JF, van Dijk TH, Plösch T, Kuipers F, Verkade HJ. The effects of intrauterine malnutrition on maternal-fetal cholesterol transport and fetal lipid synthesis in mice. Pediatr Res. 2010;68(1):10-5.

\section{Correspondence:}

Honório Sampaio Menezes

Instituto de Cardiologia

Av. Princesa Isabel, 370

90620-001 Porto Alegre - RS Brasil

Tel./Fax: (55 51)3219-2802

hsmenezes@,computech.com.br

Received: August 25, 2011

Review: October 20, 2011

Accepted: November 21, 2011

Conflict of interest: none

Financial source: FAPIC

${ }^{1}$ Research performed at Institute of Cardiology, Cardiology University Foundation (IC/FUC), Porto Alegre-RS, Brazil. 